\title{
SMALL RUMINANTS OWNERSHIP PATTERN AND LEVEL OF VETERINARY CONSULTATION UNDER TRADITIONAL SYSTEM OF MANAGEMENT IN ONDO AND EKITI STATE OF NIGERIA
}

\author{
Osho I.B., Fasina O.O., Researchers \\ Federal University of Technology, Akure, Nigeria \\ Email: oshobami@gmail.com, royalambfuta@gmail.com \\ Phone: +234-8034708795, +234-8066649331
}

\begin{abstract}
Ownership pattern and level of veterinary consultation among small ruminant farmers under the traditional system of management was assessed in Ondo and Ekiti states. Data from One hundred and ninety six (196) purposively sampled households were presented using frequency tables and percentages. Regression analysis was used to determine factors influencing level of veterinary consultation. Results revealed that $100 \%$ of the household's owned goats while $54 \%$ of the households kept sheep. Mean household size was 7 persons while females $(65 \%)$ owned more small ruminants. Mean number of sheep kept per household was $4 \pm 5.0$ while that for goats was $10 \pm 6$. Only $50.5 \%$ of the households made veterinary consultations. Forty seven percent of these do regular veterinary consultations while the rest consulted occasionally. Significant positive correlations were found between household size and number of goats $(r=0.57, p<0.05)$ and sheep $(r=0.79, p<0.05)$ respectively while significant negative correlations were found between number of goats and number of sheep $(r=-0.11, p<0.05)$. Agricultural Extension should create greater awareness on the benefits of regular health checkups and veterinary consultations for small ruminant owners.
\end{abstract}

\section{KEY WORDS}

Veterinary consultations; Small ruminants; Ownership; Diseases; Management systems; Treatments.

According to Williamson and Payne (1978) the importance of small ruminants in the tropics in general is well recognised. FAO (1982) reported that tropical Africa has about onesixth and about a third of the total world flock of sheep and goats, respectively. Total meat produced from small ruminants in Africa was 1.3 million metric tonnes (about $16 \%$ of the world total from sheep and goats). Within Africa, sheep and goats contributed $10.9 \%$ and $8.4 \%$, respectively, of our total meat. Total meat from African sheep and goats contributed $12.0 \%$, respectively, of the world total meat production from these two species. Sheep and goats in Africa produced $8.6 \%$ and $18.2 \%$ respectively, of the world total amount of milk produced from these two species and the production from both accounted for $13.6 \%$ of milk collected from small ruminants in the World (Otchere, 2009). Small ruminants however still represent a major under exploited resource within the humid zone of Nigeria where Ondo and Ekiti states are located. In Nigeria, food animals' population is estimated at 15.2 million cattle, 23 million sheep and 28 million goats (FAO, 2006) however goat population increased by $100 \%$ in 2009 to about 54 million (FAO, 2010). They are largely kept by rural dwellers as they have no range restriction in the community. Households and individuals keep varying numbers of breeding animals, mainly goats and sheep (Okali and Upton 1984). Generally, these farmers provide no special feed, housing or other inputs, and thus production is at risk due to high mortalities from diseases. According to Ademosun (1989) Small ruminants in tropical Africa are kept under traditional extensive systems. In the arid and subhumid zones, cattle are reared with sheep and/or goats. In the humid zone, animals generally graze freely, with access to household and kitchen wastes when available. These are supplemented with bush grazing on low quality forages or browses. In some places, animals are tethered and fed kitchen wastes supplemented with zero-grazing. Sheep and goat management under traditional systems has the following characteristics (Ademosun, 1989): 
(a) stock owners are usually crop farmers (mostly arable crops in the arid and subhumid zones and tree crops in the humid zone) for whom livestock keeping is of secondary importance;

(b) most households keep only a few sheep and goats, also keeping other livestock such as pigs, horses, chickens and domestic animals such as cats and dogs;

(c) the flock structures do not reflect good breeding strategy;

(d) veterinary and livestock improvement services are minimal; and

(e) the management systems are not integrated with crop production.

These management practices are not ideal. Mortality rates (particularly amongst the young) and losses from accidents, theft and predators are high. Research innovations and extension services have little impact on the production systems, and the benefits of an integrated crop/livestock production system are lost.

Diseases hinders production directly, by causing death, or indirectly by restricting growth rates and reproductive performance (Adeoye; 1984). In West Africa, Peste de Petit Ruminants (PPR) is endemic. Studies by ILCA scientist in south west Nigeria (Mack, 1982) showed that dipping with gammatox against ectoparasites and annual vaccination against PPR very dramatically reduced mortality and increased small stock numbers in village flocks. It was observed that mortality among sheep and goats in the ILCA studies decreased by $75 \%$. While death rate was reduced, offtake rate did not increase and, therefore, flock inventories rose. An efficient, well-planned animal health service is thus a pre-requisite for increasing small ruminant production in tropical Africa.

Studies have shown that among the free-roaming flocks of sheep and goats in southwest Nigeria, Peste des Petitis, Ruminants (PPR) and Sarcoptic mange (Adeoye 1984, Osho 2000) are major causes of morbidity and mortality particularly among others diseases identified in small ruminants. Trypanosomiasis has limited livestock production and most resident animals are the indigenous trypanosomiasis tolerant dwarf sheep and goats. Cost benefit analysis as reported by Otchere (2009), demonstrated that annual vaccination against PPR was viable under south west Nigeria conditions. In a study of the incidence of diseases at the goat unit of the Obafemi Awolowo University in south west Nigeria, helminthiasis was the most frequent but decreased with adequate management and vaccination interventions.

This paper therefore examines the ownership pattern of these small ruminants and also assesses the level of veterinary consultation among the rural communities in the two states. The study also tested an hypothesis at the 0.05 level of significance which is stated below:

$\mathrm{H}_{0}$ : there is no significant relationship between the ownership of small ruminants and selected socio economic characteristics of respondents households.

\section{RESEARCH METHODOLOGY}

Description of study area. The primary data for this study were collected in Ondo and Ekiti State, these states are located in the southwestern part of Nigeria. Within these states, there are three distinct ecological Zones. The mangrove forest to the south, the rainforest in the middle-belt and the derived savanna to the North. These states are well suited for the production of crops and raising of livestock. However the livestock potential has not been fully tapped, especially in the northern parts of the zones that are more suited to livestock production. Most of the livestock farmers are small-scale farmers and rely on crop production as an alternative source of income. For most of the farmers extensive system is practiced, whereby animals are allowed to graze randomly during the day and return home at evening.

Sampling Technique and Sample size. For this study, both purposive and random selection methods were used to select the respondent livestock farmers. In the first stage of selection, Northern local governments' areas of both states where livestock farmers are commonly reared were selected. The second stage of selection involved a purposive selection of households from the selected local government Areas, who reared small ruminants. Two hundred respondents from each state were targeted for the survey but four interview schedules were found unusable. In all, 196 households were sampled on both 
socio-economic life and production activities of the respondents. Specifically, data collected involved types of livestock inputs used in production, veterinary services obtained, level of education, family size and other socio-economic variables of the respondents.

Method of Data Analysis. For this study both descriptive statistics and econometric methods were used in data analysis.

In order to determine the type and magnitude of relationship that exists between the level of veterinary consultation and some variables of interest, a regression model was specified for the data. The regression model shows the relationship that exists between the dependent variable and the independent variables. For this study, two regression models were specified. For each of the models, three different functional forms of the models (i.e. the linear form, the semi-log form and the Cobb-Douglas form) were tried and the best for each of the models was selected to provide the lead of equation.

For the model, level of veterinary consultation is postulated to be influenced by sex of the respondents, livestock population (goats and sheep), level of education of respondent and household size of respondents.

The linear form of the model postulated was:

$Y=\beta_{\circ}+\beta_{1} X_{1}+\beta_{2} X_{2} \beta_{3} X_{3}+\beta_{4} X_{4}+\beta_{5} X_{5}+e_{i}$

Where

$Y=$ Number of veterinary consultation

$X_{1}=$ Sex of (the owner of the livestock) respondent

$\mathrm{X}_{2}=$ Total no of goats

$X_{3}=$ Total no of sheep

$\mathrm{X}_{4}=$ Level of education of respondent

$X_{5}=$ household size

$\mathrm{e}_{\mathrm{i}}=$ error term which could take care of error of measurement

$\beta_{0 . \ldots} \beta_{5}=$ are the unknown parameter (coefficients) to be estimated

The Semi-log form of the model postulated was:

$Y=\beta_{\circ}+\beta_{1} \log X_{1}+\beta_{2} \log X_{2} \beta_{3} \log X_{3}+\beta_{4} \log X_{4}+\beta_{5} \log X_{5}+e_{i}$

Where the variables are as defined earlier

Log = natural logarithm

The Cobb-Douglas form of the model postulated was:

$\log Y=\beta_{\circ}+\beta_{1} \log X_{1}+\beta_{2} \log X_{2} \beta_{3} \log X_{3}+\beta_{4} \log X_{4}+\beta_{5} \log X_{5}+e_{i}$

Where the variables are as earlier defined.

Statistical Analysis. Collated data were subjected to simple proportion, percentage distribution, mean values (Descriptive statistic). The assessment of ownership pattern and flock size was analyzed using econometric analysis (Shazame econometric computer package by Greene, published by McGraw-Hill (1993).

\section{RESULTS AND DISCUSSION}

Socio-economic characteristics. Results of socio-economic variables are presented on Table 1. Of the One hundred and ninety six (196) households interviewed $100 \%$ of the household's owned goats and $54 \%$ of the households kept sheep. Females (65\%) owned more small ruminants than males' farmers (34\%). The mean household size was 7 persons. The average number of sheep kept per household was $3.5 \pm 5.0$ while mean value for goats per household was $10 \pm 6$. It was observed that $50.5 \%$ of the household visited do not make veterinary consultations. Forty seven percent of them do regular veterinary consultations while the rest consulted occasionally.

Small ruminants' ownership pattern. The data from this survey indicated that in rural areas every household owned goats and half of the households in the areas keep sheep. Goats are more in demand for use during festivities, and this may account for the general interest in its production. The study also indicated that female owned more small ruminants than their male counterparts. The higher number of female owners could be explained by their availability at home while their male counterparts are engaged in either farm work or 
other duties which required devotion of time and long stay outside the environment. The female owners also see the animals as moving capital, deriving income from it whenever the need arose. The study also revealed that Veterinary calls are usually made only when health problems arise and this may explain the high percentage of those who make occasional veterinary calls.

Table 1 - Small ruminant ownership and veterinary consultation

\begin{tabular}{|c|c|}
\hline Variables & Values \\
\hline Total household visited & 196 \\
\hline Number of female owners of small ruminant & $128(65 \%)$ \\
\hline Number of male owners of small ruminant & $68(34.5 \%)$ \\
\hline Households with sheep & $106(54 \%)$ \\
\hline Households with goats & $196(100 \%)$ \\
\hline Mean values of household size & $7.0 \pm 4.38$ \\
\hline Mean value of sheep per house hold & $3.5 \pm 5.0$ \\
\hline Mean value of goat per house hold & $10 \pm 6.0$ \\
\hline Number of household that consult veterinarian & $99(50.5 \%)$ \\
\hline
\end{tabular}

Source: Field survey

Correlation Analysis. The result of correlation analysis (Table 2) showed that some variables have positive coefficients while others have negative coefficients. However, not all of them were significant at the 0.05 level of significance. A negative correlation was found between the number of goats kept and the number of sheep kept $(r=-0.11)$. This was significant at the 0.05 level of significance implying that as the number of goats kept increases, the number of sheep kept decreases. A significant and positive correlation was found between the number of goats kept and the household size $(r=0.57)$. This was also true for the correlation between number of sheep and household size $(r=0.79)$. This implies that the higher the household size the higher the number of small ruminants kept. This could be because there will be more hands to monitor them as well as the fact that they serve as 'living bank' in case of emergencies. More so since individuals within the household could keep/own their own animals, there will definitely be an increase in small ruminant population per household when we have larger household sizes.

Table 2 - Results of Pearson Product Moment Correlation Analysis

\begin{tabular}{|c|c|c|c|c|c|}
\hline $\mathrm{n} / \mathrm{n}$ & $\begin{array}{l}\text { Total } \\
\text { goat }\end{array}$ & $\begin{array}{l}\text { Total } \\
\text { sheep }\end{array}$ & $\begin{array}{l}\text { Total goats } \\
\text { and sheep }\end{array}$ & $\begin{array}{l}\text { Level } \\
\text { of education }\end{array}$ & $\begin{array}{l}\text { Household } \\
\text { size }\end{array}$ \\
\hline Total goats & 1.00 & & - & - & - \\
\hline Total sheep & $-0.111^{*}$ & 1.00 & - & - & - \\
\hline Total goats and sheep & -0.915 & 0.972 & 1.00 & - & - \\
\hline Level of education & 0.937 & -0.985 & -0.992 & 1.00 & $\begin{array}{l}- \\
-\end{array}$ \\
\hline Household size & $0.568^{*}$ & $0.796^{*}$ & $0.0376^{*}$ & -0.389 & 1.00 \\
\hline
\end{tabular}

Source: Data analysis

Regression analysis. For the three functional forms that were tried, the linear model was selected as the lead equation. The criteria for selection include the magnitude of $R$, standard error as well as the sign and magnitude of the coefficient.

The estimated regression model is presented as:

$Y=0.5734+0.013 X_{1}+0.162 X_{2}+0.425 X_{3}+0.063 X_{4}-0.039 X_{5}$

$\mathrm{R}^{2}=0.72$

Results of the regression analysis indicates that the postulated model gave a good fit for the data with the $R^{2}$ value of 0.72 , which implies that about $72 \%$ of variation in veterinary consultation is explained by the fitted model. All the variables in the model have positive signs with the exception of household size (HHS) which has a negative sign. The positive signs of the coefficient of total goats, total sheep indicate that the higher the value of these coefficients, the higher the number of veterinary consultation. The positive coefficient of the education variable implies that respondent with higher number of years of schooling have 
higher tendency for veterinary consultation. This is as a result of their better understanding of the benefits of veterinary consultations to the overall profitability of their livestock involvement. The positive coefficient of sex is also an indication that sex also influences the number of veterinary consultation by respondents. Since the dummy variable 0 represent female sex while 1 represent male sex, the value 0.013 implies that female respondents made more veterinary consultation than their male counterpart. This could be because females own more small ruminant animals than males and thus they will be more concerned about their welfare. More so since they have little disposable capital, investment in small ruminant animals tends to give them an opportunity to have reserves, thus they are more concerned that the animals do well. The negative coefficient of household size variable (HHS) implies that the variable is inversely related to the number of veterinary consultation. The higher the size of a household, the lower is the veterinary consultation. This could be because the higher household size implies higher cost of living and thus little attention is given to the welfare of the animals since most of the rural dwellers are poor resource farmers.

\section{CONCLUSION AND RECOMMENDATION}

Management is often a major factor in the success or failure of a farm enterprise. The management of the health of small ruminants even though it has been found to be very pronounced in ensuring high investment turnover for owners is still taken for granted by farmers. It is actually seen as a secondary aspect of their agro business and thus little effort is made to ensure proper veterinary consultations. The study concluded that

1. Goats were more common among the ruminants kept by households,

2. Majority consulted veterinary services occasionally

3. Higher level of education of respondents influenced frequency of veterinary consultations and

4. Household welfare will likely come ahead of veterinary welfare of animals

Government should therefore encourage more animal health rangers to visit the rural areas to give necessary services. Extension agents should also create greater awareness on the benefits of regular health checkups and veterinary consultations for small ruminant owners.

\section{ACKNOWLEDGMENT}

The assistance given by the World Bank for providing fund for this study through the National Agricultural Research Project (NARP) is acknowledged.

\section{REFERENCES}

[1] Adeoye S.A.O. 1984. Disease profile of Sheep and goats in two groups of villages in Southwest Nigeria In Proceedings of the workshop On Small ruminant production Systems in the Humid Zone of west Africa, Held in Ibadan,, Nigeria 23-26 January, 1984.

[2] Ademosun, A.A. 1989. Constraints and prospects for small ruminant research and development. Retrieved on February 10, 2012 from in Africa http://www.fao.org/wairdocs/ILRI/x5472B/x5472b02.htm

[3] FAO 2006. FAOSTAT Database. Food and Agriculture Organization, Rome, Italy.

[4] FAO 2010. Food and Agriculture Organization. Food and Agriculture Organization of the United Nations, Rome, Italy.

[5] Mack, S. 1982. Small Ruminant Breed Productivity in Africa. (Ed. R.M. Gatemby and J.C.M. Trail), ILCA, Addis Ababa, Ethiopia.

[6] Otchere, E.O. 2009. Small Ruminant Production in Tropical Africa. Retrieved on February 10, 2012 from http://www.fao.org/docrep/009/ah221e/AH221E18.htm 
[7] Opasina B.A. 1985. Health Problems among Pasture Grazed Sheep and Goats at Fasola in Southwest Nigeria. Nig. Jour. Ani. Production 12 (2) 123-129.

[8] Opasina B.A. 1987. Haemoparasities of village Goats in Southwest Nigeria. Bull Health production 35, 130-133

[9] Opasina B.A. and Onyeka E.E. 1982. Preliminary report on the incidence of trypanosomiasis. The West African Dwarf sheep and goats in Southwest Nigeria. Bull Animal Health. Prod. Afr. 30; 263-264

[10] Opasina, B.A 1985b. Health problems of Market Purchase sheep and goats in the South West Area of Nigeria. Nig. Vet. J 12(1)

[11] Steel, R.G.D., and J.N. Jorrie, 1960. Principles and Procedures of statistics McGrawHill, London.

[12] Upton M. 1984 Models of improved production systems foe small ruminants in sheep and goats in humid tropics proceedings of the workshop on small ruminants production systems in the humid zone of West Africa, 23-26 January 1984.

[13] Upton M. 1987. Goat production in humid tropics Actual and potential contribution to Agriculture development. Proceeding of a workshop at the University of Ife, lle-Ife, Nigeria, 20-24 July.

[14] Williamson, G. and W.J.A. Payne, 1978. An Introduction to Animal Husbandry in the Tropics. The English Language Book Society and Longmans, London. 